
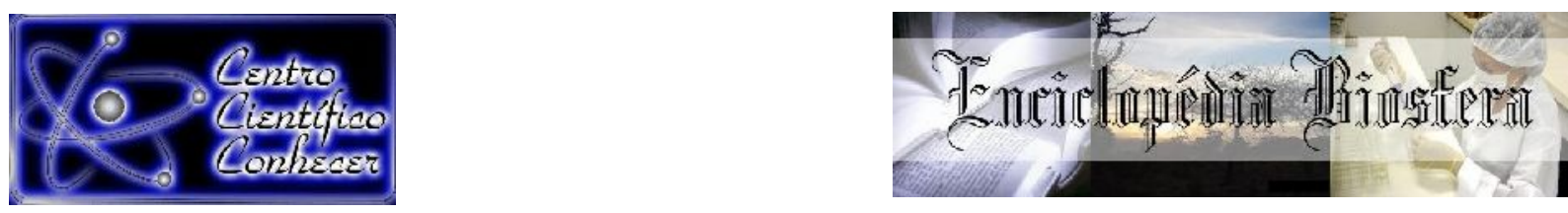

\title{
MICROFUNGOS EM SUBSTRATOS VEGETAIS SUBMERSOS EM UM CORPO HÍDRICO DE UM FRAGMENTO DE MATA ATLÂNTICA NO EXTREMO SUL DA BAHIA
}

\author{
Aline da Silva Souza ${ }^{1}$; Jorge Luiz Fortuna ${ }^{2}$
}

${ }^{1}$ Licenciada em Ciências Biológicas pela Universidade do Estado da Bahia (UNEB),

Campus X, Teixeira de Freitas-BA.E-mail: alines.souza83@hotmail.com

${ }^{2}$ Docente Adjunto da área de Microbiologia do curso de Ciências Biológicas da Universidade do Estado da Bahia (UNEB), Campus X, Laboratório de Biologia dos Fungos, Teixeira de Freitas-BA. E-mail: jfortuna@uneb.br

Recebido em: 15/05/2021 - Aprovado em: 15/06/2021 - Publicado em: 30/06/2021 DOI: 10.18677/EnciBio_2021B16

\begin{abstract}
RESUMO
Fungos desempenham importante papel em ecossistemas dulcícolas, sendo responsáveis pela decomposição de matéria orgânica de substratos submersos, transformando-os em uma fonte de nutrientes para outros seres vivos destes ecossistemas. A diversidade destes fungos nas regiões tropicais ainda é pouco conhecida, grande parte das pesquisas acontece em regiões temperadas. Este trabalho teve como objetivo identificar de espécies de microfungos associados aos substratos submersos em um corpo hídrico de um fragmento florestal de Mata Atlântica localizado na área do Programa Arboretum, no município de Teixeira de Freitas, Extremo Sul da Bahia. Foram realizadas cinco coletas de agosto de 2016 a novembro de 2017. As amostras foram transportadas para o Laboratório de Biologia dos Fungos do Campus $\mathrm{X}$ da Universidade do Estado da Bahia (UNEB). Verificou-se a presença das espécies de microfungos existentes no local estudado através da análise de constância. Foram identificados 18 (82\%) espécimes de microfungos em nível de gênero e espécie. Dos espécimes registrados os mais constantes foram do gênero Thozetella. Todos os microfungos identificados se encontram no acervo da Micoteca do Laboratório de Biologia dos Fungos do Campus $X$ da UNEB. O presente trabalho contribuiu para 0 conhecimento da diversidade de fungos na área estudada.
\end{abstract}

PALAVRAS-CHAVE: Ingoldiano; Hifomiceto; Micoteca. 


\title{
MICROFUNGI PRESENT IN SUBMERGED VEGETABLE SUBSTRATES OF A FRAGMENT OF ATLANTIC FOREST IN THE SOUTHERNMOST OF BAHIA
}

\begin{abstract}
Fungi play an important role in freshwater ecosystems, being responsible for the decomposition of organic matter of submerged substrates, transforming them into a source of nutrients for other living beings of these ecosystems. The diversity of these fungi in tropical regions is still little known, since much of the research is concerned about species found in temperate regions. Therefore, this study aimed at identifying microfungal species associated with submerged substrates in a water course of a fragment of Atlantic Forest, located in the Arboretum Program area, in the municipality of Teixeira de Freitas, Southernmost of Bahia. Five collections were performed from August 2016 to November 2017. The samples were transported to the Fungal Biology Laboratory of Campus $X$ of the State University of Bahia (UNEB). The presence of microfungal species in the studied site was verified through the constancy analysis. In total, it was possible to identify $18(82 \%)$ microfungal specimens at the level of genera and species, of which the most common recorded specimens belonged to the genus Thozetella. All identified microfungi are found in the culture collection of the Fungal Biology Laboratory of Campus $X$ of UNEB. The present work contributes to the knowledge of the fungi diversity of the studied area.
\end{abstract}

KEYWORDS: Ingoldian Fungi; Hyphomycete; Fungal Culture Collection.

\section{INTRODUÇÃO}

A Micologia é a área da Biologia que estuda os fungos, os mesmos tiveram seu grupo reconhecido como o reino Fungi por Whittaker em 1969, sendo agrupados nesse reino com base na morfologia e no modo de nutrição dos seres vivos. O reino Fungi faz parte do domínio Eukaria que agrupa todos os seres eucariontes como proposto por Carl Woese em 1990 (MORAES et al., 2009).

Os fungos se diferenciam dos demais organismos vivos por suas características próprias como: o glicogênio como substância de reserva, modo de nutrição absortiva; a parede celular composta de quitina e glucano, são eucarióticos, unicelulares ou pluricelulares, a maioria é sapróbio e filamentoso sendo os filamentos conhecidos como hifas que formam o micélio que em contato direto com o solo e com o substrato absorvem os nutrientes que são necessários para seu desenvolvimento (PETER et al., 2007).

Fungos anamórficos e conidiais, formam um grupo artificial, antes eram conhecidos como fungos deuteromicetos ou imperfeitos por apresentarem fase assexuada de reprodução, diferente dos fungos considerados perfeitos que se reproduzem sexuadamente. A incapacidade genética dos fungos conidiais para se reproduzirem sexualmente é considerada condição primitiva e se essa forma sexuada de reprodução ocorre é desconhecida, sendo assim, os fungos conidiais podem ser ascomicetos e basidiomicetos e se reproduzem somente por conídios (PETER et al., 2007).

Podem ser encontrados em ambientes terrestres (plantas, serrapilheira, solo e outros substratos), e em ambientes aquáticos (salobra, água doce ou salgada), junto às 
partes de vegetais submersos como também substratos e vegetais de origem aquática (macrófitas plantas aquáticas) são de fundamental importância para a colonização por fungos (ALEXOPOULOS et al., 1996). Os substratos vegetais alóctones são levados aos ambientes aquáticos por meio de chuvas, ventos, escoamentos de águas superficiais e assoreamentos (WONG et al., 1998).

Para Alexopoulos et al. (1996), os microfungos são organismos microscópicos distintos pela produção de esporos de origem mitótica, denominado de conídios, sua principal função é a dispersão para garantir a sobrevivência da espécie.

Os fungos conidiais de ecossistema aquático são encontrados em folhas e em substratos vegetais submersos em decomposição (MEDEIROS et al., 2009). São divididos em quatro grupos de acordo com sua morfologia e estilo de vida: fungos aeroaquáticos; fungos ingoldianos; fungos aquático-terrestres e fungos aquáticofacultativos (ALEXOPOULOS et al., 1996; GOH; HYDE, 1996; ALMEIDA et al., 2012; SILVA et al., 2014).

Os mesmos desempenham papel importante no ecossistema de água doce, sendo responsáveis pela decomposição dos substratos submersos, no processo de ciclagem de nutrientes para outros seres vivos destes ecossistemas (ALMEIDA et al., 2012). Na região tropical a diversidade dos fungos conidiais em ambientes aquáticos é pouco conhecida mesmo diante da sua importância nos ambientes de água doce. A maior parte das pesquisas concentra-se nas regiões temperadas (CHAN et al., 2000; MATHURIA; CHAUVET, 2002; TSUI et al., 2003).

De acordo com Barbosa (2011), o conhecimento sobre fungos aquáticos geralmente é negligenciado em relação à sistemática, distribuição geográfica, relação com o substrato entre outras, possuindo lacunas que devem ser descobertas. Deste modo, faz-se necessário estudos sobre fungos encontrados em substratos submersos em uma região tropical de fragmento de Mata Atlântica no Extremo Sul da Bahia.

Este trabalho teve como objetivo geral listar a diversidade de espécies de microfungos associados aos substratos submersos em um corpo hídrico de um fragmento florestal de Mata Atlântica localizado na área do Programa Arboretum de Conservação e Restauração da Diversidade Florestal, no município de Teixeira de Freitas, Extremo Sul da Bahia.

\section{MATERIAL E MÉTODOS}

O presente trabalho foi realizado em um fragmento florestal remanescente que pertence ao bioma da Mata Atlântica, com Floresta Ombrófila Densa, no qual atualmente tem sido desenvolvido o Programa Arboretum de Conservação e Restauração da Diversidade Florestal.

O local possui aproximadamente 30 ha e está localizado na região do Extremo Sul da Bahia, no município de Teixeira de Freitas (latitude 17034' Sul e longitude 3943' Oeste). Nesta área está localizado o corpo hídrico onde foram feitas as coletas de substratos submersos para pesquisa e identificação de microfungos associados a estes substratos vegetais submersos (Figura 1). 
FIGURA 1. (A) Localização de Teixeira de Freitas-BA, Extremo Sul da Bahia. (B) Localização da área de coleta (corpo hídrico), próxima ao Programa Arboretum.

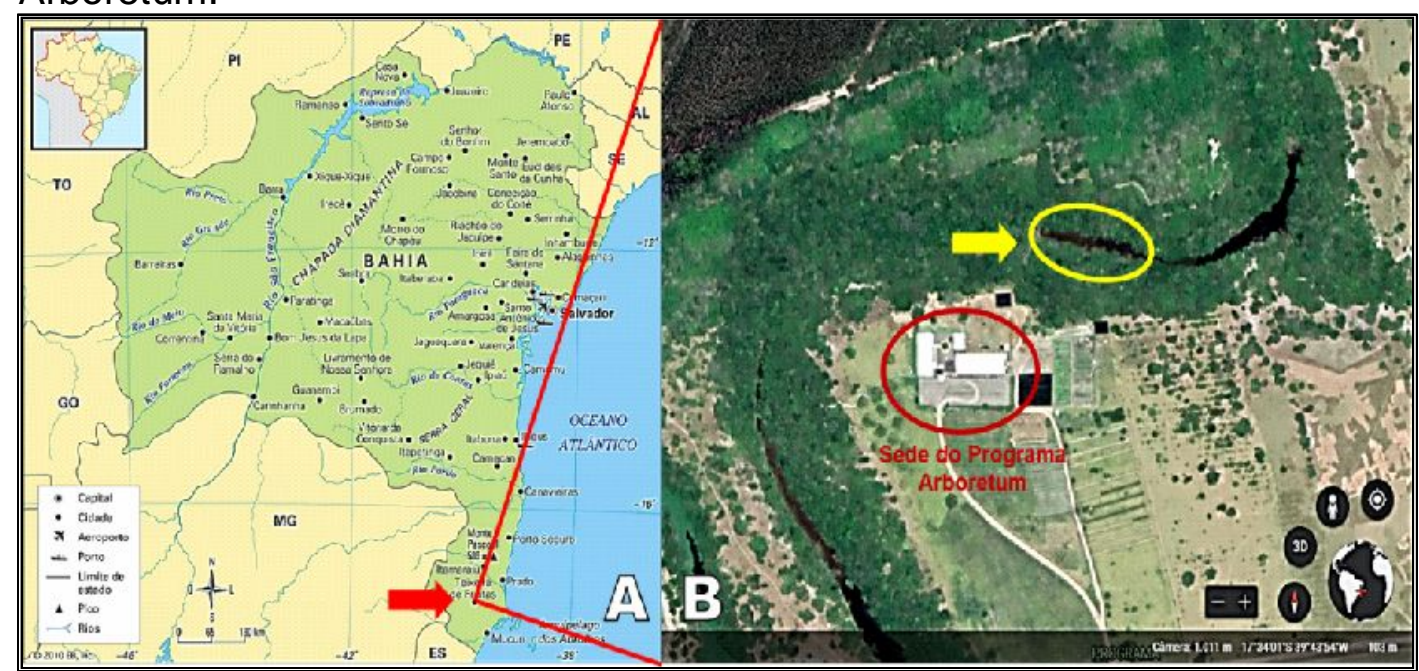

Fontes: https://br.pinterest.com/ e Google ${ }^{\circledR}$ Earth.

Foram coletadas amostras de diferentes materiais vegetais em decomposição (folhas; cascas e galhos) submersas no corpo hídrico, no mês de agosto de 2016 e nos meses de fevereiro, abril, julho e novembro de 2017 totalizando cinco coletas. Os locais de coleta foram escolhidos de acordo com a facilidade do acesso, sendo o material coletado utilizando-se uma rede do tipo puçá (Figura 2).

FIGURA 2. (A) Corpo hídrico no fragmento de Mata Atlântica. (B) Coleta de material.

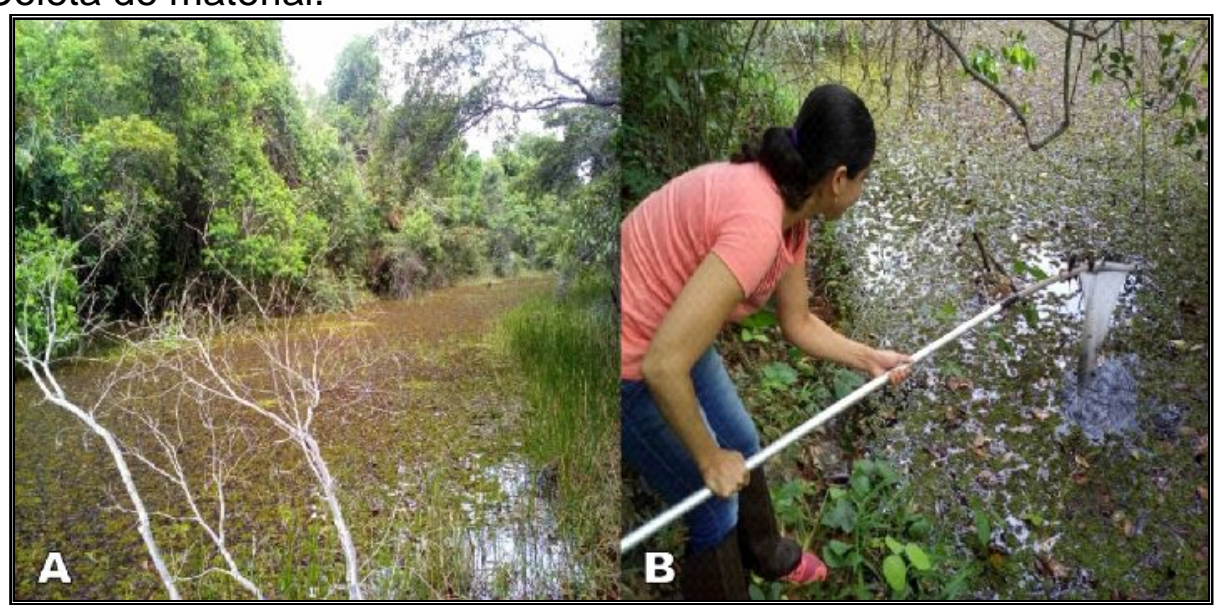

Fonte: Os pesquisadores

Depois de coletados, os substratos foram colocados em sacos plásticos e acondicionados em um recipiente isotérmico para serem transportadas para o Laboratório de Biologia dos Fungos, do Campus X da Universidade do Estado da Bahia (UNEB), para que estes fossem processados. 
Os substratos foram acondicionados em recipientes plásticos perfurados e foram lavados em água corrente por 30 minutos. Após a lavagem dos substratos, estes foram colocados sobre papel toalha, distribuídos em uma bancada, por 20 minutos para secagem e logo depois foram armazenados em placas de Petri contendo papel toalha esterilizado (câmara úmida) e acondicionados dentro de uma caixa de isopor com tampa contendo papel toalha umidificado (CASTAÑEDA-RUIZ, 2005).

Após 10 dias iniciou-se a observação do material incubado utilizando-se o estereomicroscópios (lupa). Assim que foi observada a existência do microfungo, este foi fotografado no próprio substrato. Os substratos permaneceram incubados por até 40 dias, após esse período, não havendo crescimento dos microfungos, os substratos foram descartados.

Após a observação dos microfungos no substrato coletado, estes foram isolados com auxílio de uma agulha fina, para que suas estruturas se espalhassem permitindo que ficassem mais visíveis, ajudando na identificação, e colocados em lâmina de vidro para confecção permanente de lâmina para microscopia óptica utilizando resina PVL (álcool polivinílico + ácido lático + fenol).

As lâminas confeccionadas com os microfungos foram levadas ao microscópio óptico para a observação das estruturas morfológicas de importância taxonômica (conídios, células conidiogênicas, conidióforos). As estruturas morfológicas dos microfungos foram medidas através de escala micrométrica da lente ocular do microscópio óptico e fotografadas assim que observadas, com uso de aparelho celular e câmera integrada ao microscópio e ao microcomputador.

Após as anotações das características morfológicas foi realizado o cultivo dos microfungos em placas de Petri contendo meio de cultura Ágar Cenoura Milho (CMA). A partir do substrato vegetal foram retiradas partes do microfungo, utilizando-se agulha esterilizada, e estriado em placas contendo o CMA, próximo à chama do bico de Bunsen.

As placas foram colocadas em temperatura ambiente para que ocorresse a esporulação durante três a cinco dias dependendo do crescimento do microfungo. Esse processo foi realizado para a confirmação da identificação do microfungo em nível de gênero e/ou espécie.

Depois da esporulação cada um dos microfungos foi transferido para tubos de ensaio contendo CMA inclinado, este processo é realizado próximo ao bico de Busen. Os tubos inclinados de CMA são mantidos em temperatura ambiente e após o crescimento e a esporulação dos microfungos foram cobertos e conservados com óleo mineral esterilizado e depositados na Micoteca do Laboratório de Biologia dos Fungos, do Campus $\mathrm{X}$ da UNEB.

O óleo mineral utilizado é do tipo nujol ou amerol encontrado em farmácias ou drogarias e deve ser esterilizado em autoclave a $121^{\circ} \mathrm{C} / 15 \mathrm{~min}$ em balões de fundo chato ou em Erlenmeyer tampados com algodão hidrofóbico e depois dessecado, para retirar a água de condensação, em uma estufa a 170-180ㄷ por uma hora.

Após o resfriamento foi colocada a quantidade de óleo suficiente na cultura que se desejava preservar de modo que a mesma ficasse totalmente coberta pelo óleo (PUTZKE; PUTZKE, 2013). Isto impede a desidratação e reduz a atividade metabólica, assim como a velocidade de crescimento do microrganismo, devido à redução da 
tensão do oxigênio. Logo após a submersão as culturas foram guardadas com o óleo mineral na posição vertical. Caso seja necessário podem ser realizados testes de viabilidade periodicamente para determinar se a cultura está deteriorando ou não (MORAES et al., 2009). Os microfungos foram preservados utilizando a técnica de conservação em água esterilizada (Método Castellani) (CASTELLANI, 1939).

Os dados obtidos nas observações para a identificação dos microfungos foram comparados, com os já registrados pela bibliografia especializada em microfungos disponível no acervo do Laboratório de Biologia dos Fungos, do Campus X da UNEB.

Com o objetivo de formar uma Micoteca, a coleção resultante do cultivo dos microfungos tal como as lâminas confeccionadas e identificadas foram armazenadas em caixas de papelão juntamente com o respectivo substrato vegetal e identificadas através de uma ficha da Micoteca.

Também os tubos de ensaio inoculados com os microfungos e os fracos com água destilada esterilizada contendo os cubos de Ágar com microfungos, foram preservados, identificados e depositados na Micoteca do Laboratório de Biologia dos Fungos, do Campus X da UNEB.

Foram feitas análises de constância $(\mathrm{C} \%=(p / \mathrm{P}) \times 100)$ para verificar a diversidade de microfungos presentes na área estudada; onde $\mathrm{C} \%=$ constância em porcentagem; $p$ = número de coletas contendo a espécie estudada; e $\mathrm{P}=$ número total de coletas efetuadas.

Dajoz (1978) descreveu que análise de constância é a relação em forma de porcentagem. Calcula-se o número de coletas contendo a espécie com a quantidade de coletas realizadas. A análise demonstra se a espécie é constante, acessória ou acidental. Espécies constantes quando presentes em mais de $50 \%$ das coletas, espécies acessórias quando presentes em 25 a $50 \%$ das coletas e espécies acidentais quando presentes em menos de $25 \%$ das coletas.

\section{RESULTADOS E DISCUSSÃO}

Neste estudo foram analisados 22 espécimes de microfungos sendo que $18(82 \%)$ foram identificados em nível de gênero e espécie e quatro (18\%) não foram identificados. Todos os microfungos identificados estavam associados ao material vegetal submerso em decomposição em um corpo hídrico de um fragmento de Mata Atlântica, no Extremo Sul da Bahia.

O corpo hídrico é representado por uma represa artificial, sendo classificada como ambiente lêntico. Este ambiente, segundo Silva et al. (2014) e Wong et al. (1998), apresenta menor número de fungos devido a deficiência na concentração de oxigênio.

Dos $18(82 \%)$ microfungos identificados todos foram classificados no filo Ascomycota do subfilo Pezizomycotina, sendo divididos em duas classes: Sordariomycetes e Dothideomycetes (Quadro 1). A classe Sordariomycetes apresentou indivíduos de três ordens: 14 (77\%) indivíduos da ordem Chaetosphaeriales, dois (11\%) indivíduos Hypocreales e um (6\%) indivíduo da ordem Xylariales. A classe Dothideomycetes apresentou um (6\%) indivíduo da ordem Capnodiales. 
QUADRO 1. Classificação dos microfungos.

\begin{tabular}{|c|c|c|c|}
\hline CLASSE & ORDEM & FAMILIA & GÉNERO \\
\hline \multirow{3}{*}{ Sordariomycetes } & Xylariales & Beltraniaceae & Beltrania \\
\cline { 2 - 4 } & Chaetosphaeriales & Chaetosphaeriaceae & Thozetella \\
\cline { 2 - 4 } & Hypocreales & Nectriaceae & Volutella \\
\hline Dothideomycetes & Capnodiales & Cladosporiaceae & Cladosporium \\
\hline
\end{tabular}

Para Goh e Hyde (1996), dos grupos de fungos presentes em ambientes aquáticos de água doce, os basidiomicetos são pouco frequentes e possuem um número considerado muito baixo de espécies registrada. No ambiente de água doce, os grupos mais representativos são compostos por integrantes do filo Ascomycota (SHEARER et al., 2007).

Os gêneros e espécie identificados na área de estudo, com exceção de Volutella, já haviam sido registrados em outros estudos com microfungos associados a substratos vegetais submersos de fragmento de bioma de Mata Atlântica na Bahia (BARBOSA, 2011) e no bioma da Caatinga na Bahia, Ceará, Paraíba e Piauí (SILVA et al., 2014). Porém, não havia nenhum registro na região do Extremo Sul da Bahia. Sendo assim, os dados levantados neste estudo possibilitam novas pesquisas, além de favorecer 0 conhecimento da micodiversidade em uma região que não havia dados sobre estes fungos.

Todos os táxons identificados neste estudo foram registrados em estudo realizado por Santana et al. (2017), porém neste estudo os microfungos estavam associados à serrapilheira, em ambiente terrestre, da Mata Atlântica e Caatinga na Bahia. Os estudos de Barbosa (2011); Silva et al. (2014); Santana et al. (2017) foram também realizados na região Nordeste.

Barbosa (2011) identificou microfungos associados a substratos vegetais submersos em ambientes lóticos, em fragmentos de Mata Atlântica, na Serra da Jibóia, no estado da Bahia. Silva et al. (2014) realizaram levantamento taxonômico de fungos conidiais associados a substratos vegetais submersos, em diversos ambientes lóticos de diferentes áreas inseridas no bioma Caatinga no Ceará e Bahia. Já Santana et al. (2017) levantaram a riqueza de microfungos da serapilheira em um fragmento de Mata Atlântica, no município de Cruz das Almas-BA e em uma área de Caatinga, no município de Saúde-BA, demonstrando baixa similaridade entre os dois biomas.

$\mathrm{Na}$ região Norte foi realizado estudo por Monteiro (2014), sobre fungos conidiais associados a substratos vegetais submersos em fragmentos do bioma Amazônia no Pará, apresentou três dos gêneros e espécie do presente estudo com exceção de Cladosporium, constatando a distribuição geográfica desses fungos em outra região além da estuda.

A espécie Beltrania rhombica foi encontrada em todos os estudos citados a cima, sendo encontrada tanto em ambiente terrestre quanto em ambiente aquático e distribuída geograficamente na região Nordeste e Norte do Brasil. Os resultados encontrados, neste estudo na região do Extremo Sul, revelam que os fungos conidiais identificados foram considerados fungos aquático-facultativos, já que estes são fungos encontrados em ambiente terrestre e aquático podendo esporular e dispersar seus conídios em ambos os ambientes, além de poderem se desenvolver sobre substratos vegetais submersos ou terrestres.

ENCICLOPÉDIA BIOSFERA, Centro Científico Conhecer - Jandaia-GO, v.18 n.36; p. 229 
Foi observado o aspecto ecológico de constância das espécies dos fungos encontrados em relação às coletas, conforme preconizado por Dajoz (1978). Das cinco coletas realizadas o gênero Thozetella apresentou-se em três coletas sendo este com maior ocorrência. Seguido de Volutella ciliata que ocorreu em duas coletas. Já o Cladosporium sp. e Beltrania rhombica ocorreram cada um em uma coleta (Tabela 1).

TABELA 1. Aspecto ecológico de constância dos microfungos identificados.

\begin{tabular}{ccccccc}
\hline MICROFUNGOS & $\mathbf{1}$ & $\mathbf{2}$ & $\begin{array}{c}\text { COLETAS } \\
\mathbf{3}\end{array}$ & $\mathbf{4}$ & $\mathbf{5}$ & $\mathbf{C} \%$ \\
\hline Beltrania rhombica & $\mathbf{X}$ & & & & & $20 \%$ \\
Cladosporium sp. & & $\mathbf{X}$ & & & & $20 \%$ \\
Thozetella sp. 01 & & & $\mathbf{X}$ & & & $20 \%$ \\
Thozetella sp. 02 & & & $\mathbf{X}$ & $\mathbf{X}$ & & $40 \%$ \\
Thozetella sp. 03 & & $\mathbf{X}$ & & & $20 \%$ \\
Thozetella sp. 04 & & & $\mathbf{X}$ & & $20 \%$ \\
Thozetella sp. 05 & & & $\mathbf{X}$ & & $20 \%$ \\
Thozetella sp. 06 & & & & $\mathbf{X}$ & $20 \%$ \\
Volutella ciliata & & $\mathbf{X}$ & & & $\mathbf{X}$ & $40 \%$ \\
\hline
\end{tabular}

Verificou-se que dos espécimes identificados, as espécies $B$. rhombica; Cladosporium sp.; Thozetella sp. 01, Thozetella sp. 03, Thozetella sp. 04; Thozetella sp. 05; e Thozetella sp. 06 ocorreram em $20 \%$ do total de coletas realizadas, classificandoos na categoria de espécies acidentais, quando se faz presente em menos de $25 \%$ das coletas. A espécie Thozetella sp. 02 e a espécie Volutella ciliata ocorreram em $40 \%$, classificando-as na categoria acessória, quando presente em $25 \%$ a $50 \%$ das coletas, segundo Dajoz (1978).

Neste estudo sete $(77,78 \%)$ dos táxons foram classificados na categoria acidental e dois $(22,22 \%)$ na categoria acessória. Além disso, observou-se que os táxons do gênero Thozetella foram classificados nas categorias acidental e acessória. Nenhum táxon, do presente estudo, foi classificado como constante. Os táxons identificados por Monteiro (2014) de maior frequência, nas três áreas estudadas, se classificaram na categoria acidental e com menor frequência na acessória e constante.

No estudo realizado por Santana et al. (2017), de microfungos associados à serapilheira na Mata Atlântica e Caatinga, onde os fungos foram classificados como acidental $(61,54 \%)$, acessória $(20,51 \%)$ e constante $(17,95 \%)$ no fragmento de Mata Atlântica, enquanto que no fragmento de Caatinga foram classificados como acidental $(55,26 \%)$, acessória $(23,68 \%)$ e constante $(21,05 \%)$. Tais resultados revelam-se semelhante ao presente estudo realizado na região do Extremo Sul da Bahia, onde a maioria dos fungos identificados foi classificada como acidental.

Os diferentes substratos utilizados na pesquisa foram cascas, galhos e folhas. No substrato casca não foram registrados a ocorrência de microfungos. Dos substratos, a maior relevância para a ocorrência de microfungos foram as folhas, onde foram encontrados microfungos em $21(95,5 \%)$ folhas, enquanto que em galhos só foi encontrado uma (4,5\%) vez. A espécie Thozetella sp. 4 foi encontrada associada a dois 
tipos de substratos (folha e galho). Todos os outros espécimes identificados foram encontrados somente em folhas (Tabela 2).

TABELA 2. Lista de ocorrência dos microfungos identificados nos tipos de substratos analisados.

\begin{tabular}{|c|c|c|c|}
\hline MICROFUNGOS & FOLHAS & GALHOS & TOTAL \\
\hline Beltrania rhombica & 1 & --- & 1 \\
\hline Cladosporium sp. & 1 & --- & 1 \\
\hline Thozetella sp. 01 & 4 & --- & 4 \\
\hline Thozetella sp. 02 & 2 & --- & 2 \\
\hline Thozetella sp. 03 & 1 & --- & 1 \\
\hline Thozetella sp. 04 & 1 & 1 & 2 \\
\hline Thozetella sp. 05 & 1 & --- & 1 \\
\hline Thozetella sp. 06 & 4 & --- & 4 \\
\hline Volutella ciliata & 2 & -- & 2 \\
\hline Não Identificado sp. 01 & 1 & --- & 1 \\
\hline Não Identificado sp. 02 & 1 & --- & 1 \\
\hline Não Identificado sp. 03 & 1 & --- & 1 \\
\hline Não Identificado sp. 04 & 1 & --- & 1 \\
\hline TOTAL & $21(95,5 \%)$ & $1(4,5 \%)$ & $22(100 \%)$ \\
\hline
\end{tabular}

Dos substratos vegetais em decomposição as folhas são as mais susceptíveis aos fungos, pois compõem a parte mais significativa entre os substratos vegetais, tanto pela biomassa quanto pelos nutrientes fornecidos (MEGURO et al., 1979). Além disso, segundo Silva et al. (2014), as folhas são um dos substratos mais colonizados por fungos conidiais.

\section{CARACTERÍSTICAS DOS MICROFUNGOS IDENTIFICADOS Beltrania}

O gênero Beltrania (O. Penzig, 1882, Nuovo G. Bot. Ital.,14: 72) possui colônias efusas de coloração marrom a preto, o micélio apresenta-se imerso e parcialmente superficial no substrato. Apresenta setas simples, escuras, lisas ou verrucosas, de paredes espessas. O conidióforo pode ocorrer de forma macronematosos, mononematosos, reto ou levemente flexuoso não ramificado, septado, de cor castanhoclaro, são provenientes de células basais ou de células separadas radialmente lobadas. As células conidiogênicas integradas, terminais, poliblásticas, simpodiais, clavadas ou cilíndricas. Conídios solitários, bicônicos, apendiculados, sendo a extremidade livre usualmente esculpada ou apiculada, septo liso cor olivacea a marrom escuro, célula de separação transversal, hialina, apêndice no ápice do conídio, pontiagudo (ELLIS, 1971). Este grupo apresenta fungos hifomicetos (anamórficos). Inclui mais outros quatro gêneros Beltraniella, Beltraniopsis, Hemibeltrania e Pseudobeltrania (ELLIS, 1971). No estudo realizado por Cruz (2012) o grupo Beltrania apresenta mais dois gêneros Porobeltraniella e Zelobeltraniella, totalizando sete gêneros incluindo o Beltrania. De acordo com o banco de dados disponível no site Index Fungorum (2018) o gênero Beltrania possui 18 espécies. 


\section{Beltrania rhombica}

Material examinado: BRASIL, Bahia: Teixeira de Freitas, represa artificial, folha submersa em decomposição, 20/08/2016; Souza. A. S. Foi identificado apenas um indivíduo da espécie Beltrania rhombica Penz, apresentando conidióforo simples, reto, septado, liso castanho-claro 120-123 $\mu \mathrm{m}$. Células de separação presentes, hialinas. Conídios bicônicos, apendiculado, solitários, lisos, sem septos, castanho-claro, 17,5-28 x 10-13 $\mu \mathrm{m}$. Apêndice de 5-10 $\mu \mathrm{m}$ (Figura 3). As características observadas concordam com as descritas por Ellis (1971).

FIGURA 3. Beltrania rhombica. (A) Aspecto geral e conidióforo (cf) 120-123 $\mu \mathrm{m}$, aumento de 400X. (B) Conídio (co) 17,5-28 $\mu \mathrm{m}$ e célula de separação (cs), aumento de $1.000 \mathrm{X}$.

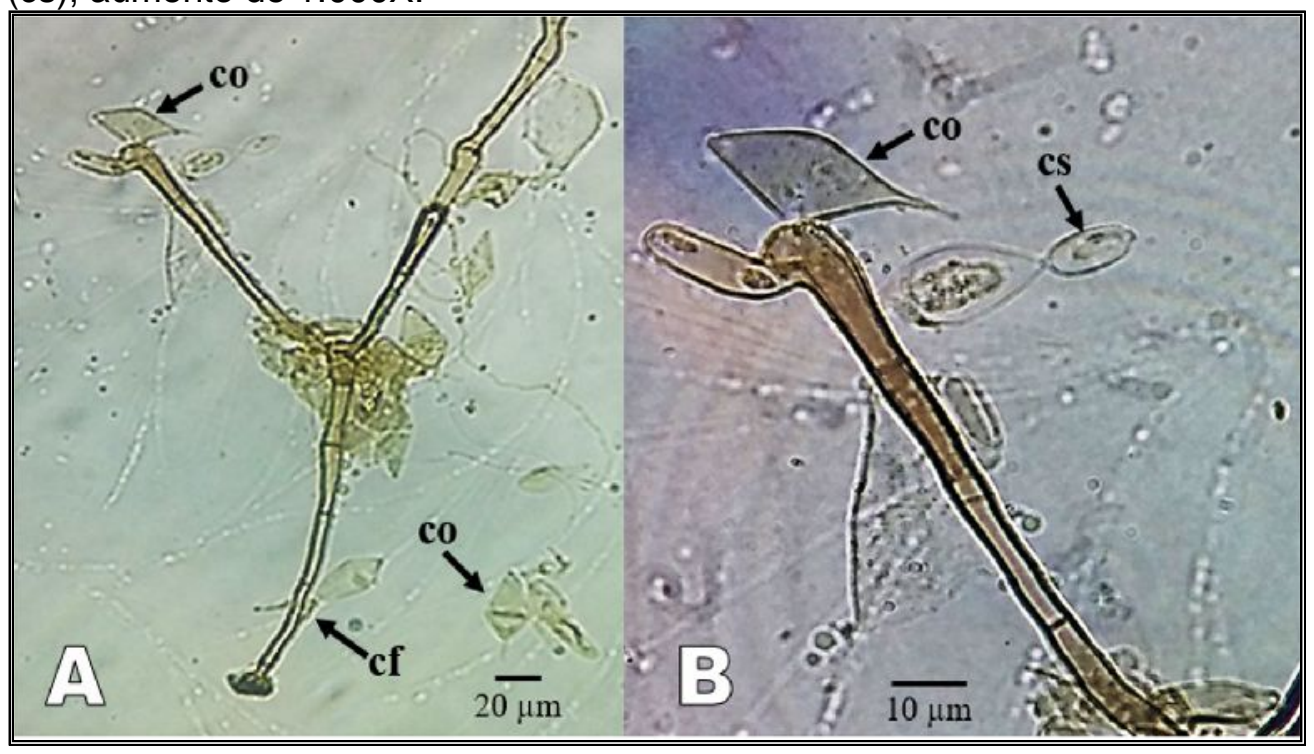

\section{Cladosporium}

Os indivíduos do gênero Cladosporium (Link ex Fries; Link, 1815, Magazin Ges. Naturf. Freunde Berlin 7: 37-38; Fries, 1821, sit. Mycol., 1: XLVI) são hifomicetos, apresentam colônias efusas e às vezes puntiformes, de cor olivácea podendo ser acinzentadas à marrom escuro. A superfície do fungo aparenta ter pelos. O micélio é imerso e muitas vezes superficial no substrato. Os conidióforos são macronematosos podendo ser micronematosos em alguns casos. Os conidiofóros macronematosos normalmente são retos ou flexíveis, não ramificados ou com ramificações restritas na região apical, formando um estipe ou uma cabeça de coloração marrom-olivácea à marrom. As células conidiogênicas são poliblásticas, integradas, terminais, intercalares, simpodiais, cilíndrica, cicatrizadas. Os conídios podem ser produzidos em cadeias, sendo catenulados, podem ser solitários, em algumas espécies apresentam grandes conídios, são simples, cilíndricos, ovoides, fusiformes, elipsoides, esféricos ou subesféricos. Muitas vezes com cicatriz distintamente protuberante em cada extremidade no final de cada conídio. Possuem coloração marrom-olivácea escuro ou marrom, a superfície do conídio pode ser lisa, verrugosa ou equinulada com 0-3 septos 
ocasionalmente (ELLIS, 1971). Nos dados disponíveis no site Index Fungorum (2018) o gênero Cladosporium possui 816 espécies.

\section{Cladosporium sp.}

Material examinado: BRASIL, Bahia: Teixeira de Freitas, represa artificial, folha submersa em decomposição, 08/03/2017; Souza. A. S. Foi identificado apenas um indivíduo do gênero Cladosporium apresentando conidióforo macronematoso reto, marrom-oliváceo. Células conidiogênicas integradas, terminais, cicatrizada. Conídios em cadeia, fusiformes, lisos, com cicatriz no final do conídio, não septado, marromoliváceo. Conídios medem 6-19 x 3-4 $\mu \mathrm{m}$ (Figura 4). Características concordam com as descritas por Ellis (1971) para o gênero.

\section{Thozetella}

O gênero Thozetella (Kuntze, 1891) é um hifomiceto, anamorfo de Ascomycota que apresenta os esporodóquios constituídos pelo conidióforos curtos e células conidiogênicas, os sinemas são eretos, compactados, longos, estreitos, robustos. Os conidióforos ramificados, septados, lisos, eretos e castanho-claros a castanhos. Células conidiogênicas monofialídicas, terminais, integradas, lisas e castanho-claras a hialinas. Os conídios lunados, fusiformes, com e sem septos, lisos e hialinos e com e sem sétula filiforme nas extremidades, são morfologicamente muito semelhantes entre as espécies. Apresenta microawns (microarista) células estéreis que surgem das células conidiogênicas e são localizadas no ápice e ao redor da massa mucilaginosa de conídios, são distintas a cada espécie (SILVA, 2012). O site Index Fungorum (2018) informa que Thozetella possui 22 espécies.

FIGURA 4. Cladosporium sp. (A) Conidióforo macronematoso (cf) e células conidiogênicas (cc) cicatrizadas, aumento de 400X. (B) Conídios (6-19 x 3-4 $\mu \mathrm{m})$, aumento de 1.000X.

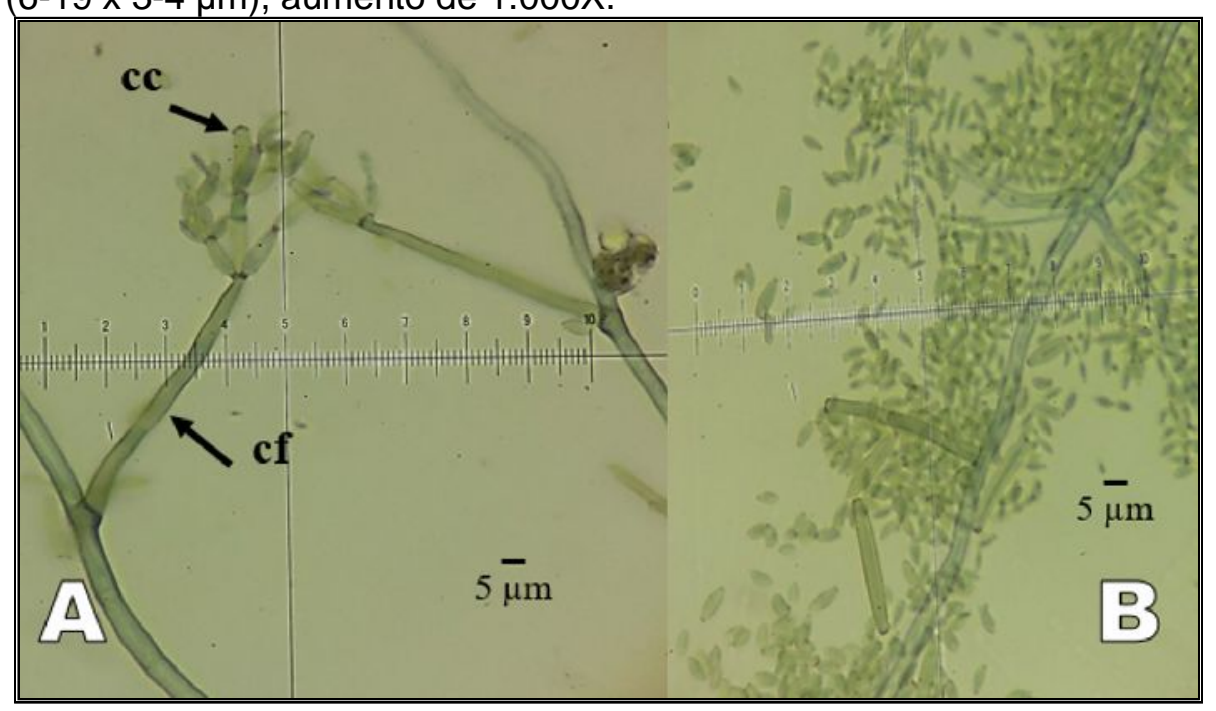




\section{Thozetella sp. 01}

Material examinado: BRASIL, Bahia: Teixeira de Freitas, represa artificial, folha submersa em decomposição 13/04/2017, Souza. A. S. Foram identificados quatro indivíduos apresentando conidioma curto tipo esporodóquios e eretos tipo sinema de cor castanho a marrom. Apresentam células estéreis (microaristas) localizadas no ápice e ao redor da massa mucilaginosa de conídios. Conídios, fusiformes, hialinos, solitários, lisos, 5-15 x 1-3 $\mu \mathrm{m}$, com sétula 4-7 $\mu \mathrm{m}$ de comprimento em cada uma das extremidades do conídio (Figura 5). Características observadas concordam com as descritas por Silva (2012).

\section{Thozetella sp. 02}

Material examinado: BRASIL, Bahia: Teixeira de Freitas, represa artificial, folha submersa em decomposição 13/04/2017 e 15/07/2017, Souza. A. S. Foram identificados dois indivíduos apresentando conidioma de cor castanho-claro, ereto do tipo sinema. Células estéreis (microaristas), hialina vermiformes em forma de L, localizadas no ápice da massa mucilaginosa de conídios 35-90 × $2 \mu \mathrm{m}$. Conídios, fusiformes, hialinos, solitários, lisos, septados 10-15 x 1-2 $\mu \mathrm{m}$ (Figura 5). Características concordam com as descritas por Silva (2012).

\section{Thozetella sp. 03}

Material examinado: BRASIL, Bahia: Teixeira de Freitas, represa, folha submersos em decomposição 13/04/2017, Souza. A. S. Foi identificado apenas um indivíduo apresentando conidioma do tipo sinema, cor castanho-amarronzado. Células conidiogênicas unidas ao conidióforo castanho-amarelado. Conídios, fusiformes, solitários, lisos, castanho-amarelado, septados 12,5-15 x 2-2,5 $\mu \mathrm{m}$. Células estéreis (microaristas) em forma de L localizada no ápice e ao redor da massa de conídios, hialinas 67-100 x 2-2,5 $\mu \mathrm{m}$ (Figura 5). Características concordam com as descritas por Silva (2012). 
FIGURA 5. (A) Thozetella sp. 01. Conidioma do tipo sinema (aumento 100X). (B) Thozetella sp. 01. Conídios (co) 5-15 x 1-3 $\mu \mathrm{m}$ (1.000X). (C) Thozetella sp. 02. Conidioma do tipo sinema (100X). (D) Thozetella sp. 02. Conídios septados (co) (1.000X). (E) Thozetella sp. 03. Conidioma do tipo esporodóquio (100X). (F) Thozetella sp. 03. Células estéreis (ce) $67-100 \times 2$ 2,5 e conídios (co) (1.000X). (G) Thozetella sp. 04. Conidioma do tipo sinema (cd) e conídios (co) (100X). (H) Thozetella sp.05. Conidioma do tipo sinema (100X). (I) Thozetella sp.05. Conídios (co) 12-15 x $2 \mu \mathrm{m}$ (1.000X). (J) Thozetella sp. 06. Conidioma do tipo esporodóquio (400X). (K) Thozetella sp. 06. Células conidiogênicas (cc) (400X). (L) Thozetella sp. 06. Conídios
(co)
10-16
$\mathrm{X}$
1,0
$\mu \mathrm{m}$

$(1.000 \mathrm{X})$.

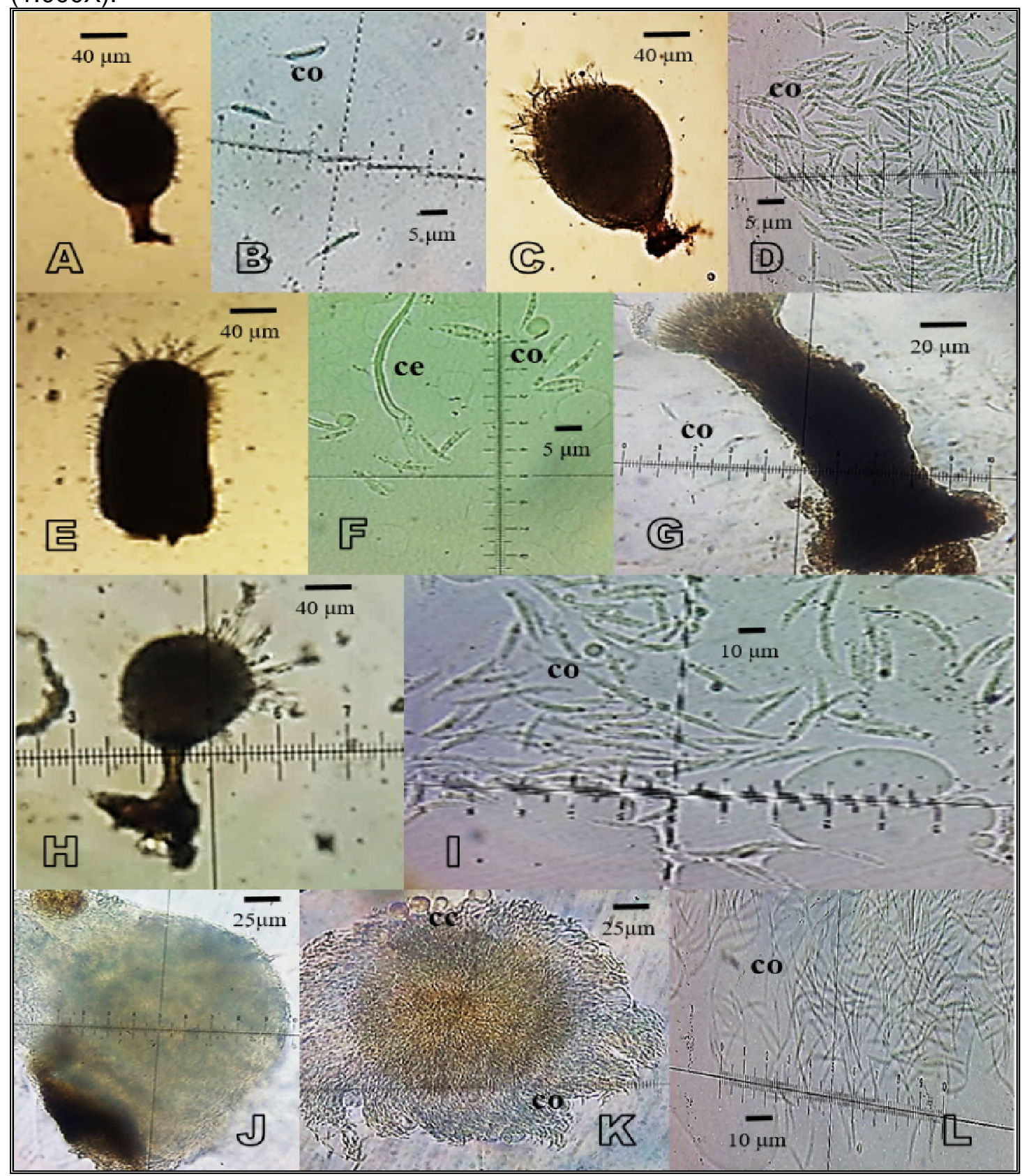

ENCICLOPÉDIA BIOSFERA, Centro Científico Conhecer - Jandaia-GO, v.18 n.36; p. 235 


\section{Thozetella sp. 04}

Material examinado: BRASIL, Bahia: Teixeira de Freitas, represa artificial, folha/galho submersos em decomposição 15/07/2017, Souza. A. S. Foram identificados dois indivíduos apresentando conidioma bem robusto do tipo sinema, cor castanhoescuro, 303-325 $\mu \mathrm{m}$ de comprimento. Células conidiogênicas densamente unidas ao conidióforo. Conídios fusiformes, solitários, lisos, septados 14-15 × $2 \mu \mathrm{m}$. Células estéreis (microaristas) vermiformes em forma de $L$ localizada no ápice e ao redor da massa de conídios, hialinas $75 \times 2 \mu \mathrm{m}$ (Figura 5). Características concordam com as descritas por Silva (2012).

\section{Thozetella sp. 05}

Material examinado: BRASIL, Bahia: Teixeira de Freitas, represa artificial, folha/galho submersos em decomposição 15/07/2017, Souza. A. S. Foi identificado um indivíduo apresentando conidioma do tipo sinema, estreito, alongado cor castanho-claro $220 \mu \mathrm{m}$ de comprimento a $65 \mu \mathrm{m}$ largura na base e $40 \mu \mathrm{m}$ de largura no final do sinema. Conídios fusiformes, solitários, lisos, hialino, septados 12-15 x $2 \mu \mathrm{m}$. Células estéreis (microaristas) lunadas, hialinas, localizada no ápice e ao redor da massa de conídios 50-60 × $2 \mu \mathrm{m}$ (Figura 5). Características concordam com as descritas por Silva (2012).

\section{Thozetella sp. 06}

Material examinado: BRASIL, Bahia: Teixeira de Freitas, represa artificial, folha/galho submersos em decomposição 24/11/2017, Souza. A. S. Foram identificados quatro indivíduos com conidioma do tipo esporodóquio de cor castanho-amarronzado. Células conidiogênicas hialinas firmemente unidas ao conidioma. Conídios lunados, afilados, lisos, hialino, sem septos 10-16 x $1 \mu \mathrm{m}$. Células estéreis aparentemente ausentes no ápice ou ao redor da massa de conídios (Figura 5). Características concordam com as descritas por Silva (2012).

Os espécimes de Thozetella foram os de maior ocorrência, sendo agrupados de acordo as semelhanças dos conídios, conidioma, ausência e presença de células estéreis (microaristas). Segundo Silva (2012), o estudo morfológico demonstrou que os conidiomas, conidióforos, células conidiogênicas e conídios não são bons caracteres para delimitar as espécies. Até o momento as microaristas são as únicas estruturas que auxiliam na separação de algumas espécies, portanto sugere a utilização de outras técnicas para elucidar o conceito de espécie no gênero.

\section{Volutella}

O gênero Volutella (Fries, 1832) é um microfungo hifomiceto caracterizado por esporodóquios sésseis, pedúnculo curto, hialino e brilhante, circuncidado por setas que possui massa conidial agregada por mucilagem na parte central apresenta setas lisas, septadas, pontiagudas, longas, hialinas. Os conidióforos simples, ramificados, retos ou flexuosos, lisos, hialinos, fortemente agregados, 10-15 $\times 2-3 \mu \mathrm{m}$. As células conidiogênicas fialídicas, cilíndricas, terminais. Os conídios unicelulares, elípticos, lisos, cilíndricos, sem septo, solitários unidos por uma mucilagem 4-6 (-9) x (1,5) 2.0-2,5 $\mu \mathrm{m}$. Colônias de crescimento moderado de coloração branca a creme (DOMSCH; GAMS, 
1993). O site Index Fungorum (2018) informa que o gênero Volutella possui 144 espécies.

\section{Volutella ciliata}

Material examinado: BRASIL, Bahia: Teixeira de Freitas, represa artificial, folha submersa em decomposição, 11/02/2017 e 24/11/2017; Souza. A. S. Foram identificados dois indivíduos da espécie Volutella ciliata, apresentando conidioma do tipo esporodóquio, pedúnculo curto, liso, ornamentado por setas lisas, pontiagudas, longas, hialinas. Conídios solitários, lisos, cilíndricos, final da extremidade do conídio arredondado, 7-9 x 1-2 (Figura 6). Características apresentadas concordaram com as descritas por Domsch e Gams (1993).

FIGURA 6. Volutella ciliata. (A) Conidioma (cd) do tipo esporodóquio, setas (st) hialinas, conídios (co) (400X). (B) Conídios (co) cilíndricos, lisos 7-9 x 1-2 um (1.000X).

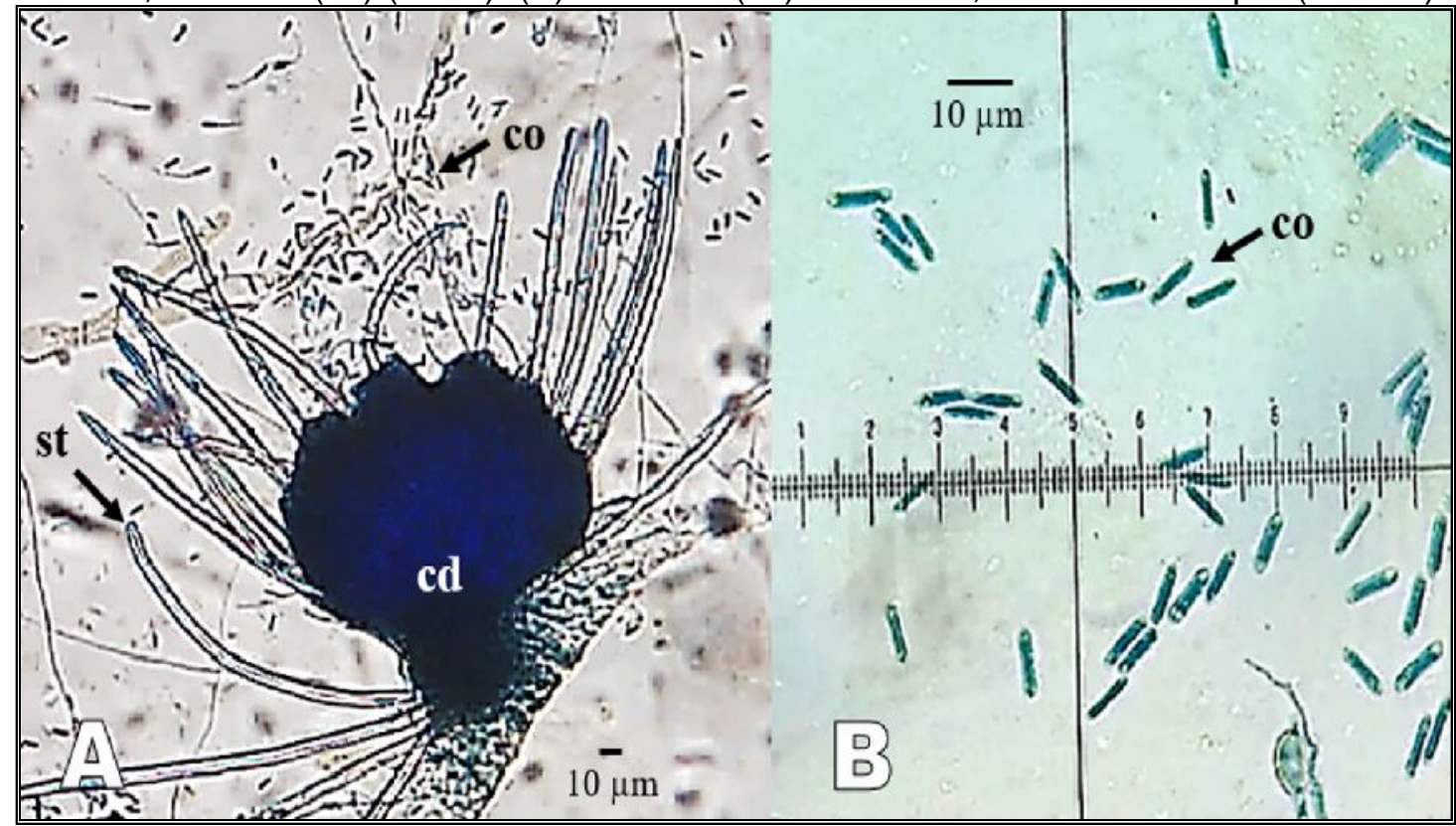

O corpo hídrico (represa artificial) presente no Programa Arboretum representa um ambiente rico em substratos constatando uma diversidade de microfungos que nunca antes estudado neste local. Sendo este estudo o pioneiro na região do Extremo Sul da Bahia.

A área estudada encontra-se inserida em fragmento de bioma de Mata Atlântica que mesmo sofrendo ações antrópicas, consegue abrigar uma biodiversidade de espécies tanto de flora quanto de fauna, em especial a diversidade de fungos.

O presente estudo permitiu ampliar o conhecimento da diversidade dos microfungos em ambiente aquático na região. O levantamento de dados obtidos a partir desse estudo servirá de base para novos estudos. Sendo assim, sugere-se continuação e investimento em pesquisas para agregar mais conhecimentos e descobertas sobre os microfungos. 


\section{CONCLUSÃO}

Foram registrados quatro gêneros e duas espécies de microfungos na área de estudo, sendo encontrados em dois tipos diferentes de substratos presentes no corpo hídrico estudado: galho e folhas, no qual as folhas foram os substratos de maior ocorrência. Todos os fungos identificados pertencem ao filo Ascomycota. A maioria das espécies registradas na área estudada são acidentais.

Primeiro registro de fungo aquático-facultativo para a região do Extremo Sul da Bahia, destacando a importância da investigação da biodiversidade desse grupo de fungos no Bioma Mata Atlântica, a fim de ampliar a distribuição geográfica desses ou dessas espécies.

\section{REFERÊNCIAS}

ALEXOPOULOS, C. J.; MIMS, C. W.; BLACKWELL, M. Introductory Mycology. 4 ed. New York: John Wiley \& Sons, Inc. 1996. 870 p.

ALMEIDA, D. A. C.; BARBOSA, F. R.; GUSMÃO, L. F. P. Alguns fungos conidiais aquático-facultativos do bioma Caatinga. Acta Botanica Brasilica. v. 26, p. 924-932, 2012. DOI: https://doi.org/10.1590/S0102-33062012000400021

BARBOSA, F. R. Microfungos associados a substratos vegetais submersos em ambiente lótico de um fragmento de Mata Atlântica, Bahia, Brasil. 245 f. Tese (Doutorado). Departamento de Ciências Biológicas. Universidade Estadual de Feira de Santana (UEFS). 2011. URL: http://tede2.uefs.br:8080/handle/tede/1083

BEGON, M.; TOWNSEND, C. R.; HARPER, J. L. Ecologia: De Indivíduos a Ecossistemas. 4 ed. Porto Alegre: Artmed, 2007. 752 p.

CAI, L.; HYDE, D.; TSUI, C. K. M. General of Freshwater Fungi. Hong Kong: Fungal Diversity Press. 2006. 261 p.

CASTAÑEDA-RUIZ, R. F. Metodología en el studio de los hongos anamorfos. Anais... $\mathrm{V}$ Congresso Latino Americano de Micologia. Associação Latino Americana de Micologia, p. 182-183, Brasília-DF, 2005.

CASTELLANI, A. Viability of some pathogenic fungi in distilled water. Journal of Tropical Medicine and Hygiene. v. 42, p. 225-226, 1939.

CHAN, S. Y.; GOH, T. K.; HYDE, K. D. Ingoldian fungi in Hong Kong. p. 89-107. In: HYDE, K. D.; HO, W. H; POINTING, S. B. (Eds.). Aquatic Mycology Across the Millennium. Fungal Diversity 5. 2000.

CRUZ, A. C. R. Revisão do grupo Beltrania (Xylariales-Ascomycota). 275 f. Tese (Doutorado). Programa de Pós-Graduação em Botânica. Universidade Estadual de Feira de Santana (UEFS). 2012. 
DAJOZ, R. Ecologia Geral. 3 ed. Petrópolis: Vozes, 1978, 474 p.

DOMSCH, K. H.; GAMS, W. Compendium of Soil Fungi, v.1-2. Braunschweig: IHWVerlag. 1993, 860 p.

ELLIS, M. B. Dematiaceous Hyphomicetes. Surrey: Commonwealth Mycological Institute. 1971.608 p.

ESTEVES, F. A. Fundamentos de Limnologia. 2 ed. Rio de Janeiro: Interciência.1998. $602 \mathrm{p}$.

FJS (Fundação José Silveira). Programa Arboretum. [online]. Disponível em: <http://www.fjs.org.br/programa-arboretum> Acessado em: setembro de 2016.

FUNDAÇÃO SOS MATA ATLÂNTICA. Atlas dos Remanescentes Florestais da Mata Atlântica, Período 2005-2008: Relatório Parcial. São Paulo: Inpe. 2009. 156 p.

$\mathrm{GOH}$, T. K.; HYDE, K. D. Biodiversity of freshwater fungi. Journal of Industrial $\begin{array}{llllll}\text { Microbiology. } & \text { v. } & 17, & \text { p. } & 328-345, & 1996 .\end{array}$ https://link.springer.com/article/10.1007/BF01574764

INDEX FUNGORUM. Index Fungorum Partnership. [online]. Disponível em: $<$ http://www.indexfungorum.org/names/Names.asp>. Acessado em 08 de janeiro de 2018.

LACAZ, S. C.; PORTO, E.; HEINS-VACCARI, M. E.; MELO, T. N. Guia para Identificação: Fungos, Actinomicetos, Algas de Interesse Médico. São Paulo: Sarvier. 1998. 445 p.

MARQUES, M. F. O. Fungos conidiais associados à decomposição de substratos vegetais em fragmento de Mata Atlântica, Serra da Jibóia, Bahia. Recife. 184 f. Dissertação (Mestrado). Departamento de Micologia. Universidade Federal de Pernambuco (UFPE). 2007.

MATHURIA, C.; CHAUVET, E. Breakdown of leaf litter in a neotropical stream. Journal of the North American Benthological Society. v. 21, n. 3, p. 384-396, 2002. URL: https://hal.archives-ouvertes.fr/hal-01333522/file/mathuriau_9652.pdf

MEDEIROS, A. O.; PASCOAL, C.; GRAÇA, M. A. S. Diversity and activity of aquatic fungi under low oxygen conditions. Freshwater Biology. v. 54, p. 142-149, 2009. DOI: https://doi.org/10.1111/j.1365-2427.2008.02101.x

MEGURO, M.; VINUEZA, G. N.; DELITTI, W. B. C. Ciclagem de nutrientes na mata mesófila secundária - São Paulo. I - Produção e conteúdo de nutrientes minerais no 
folhedo. Boletim de Botânica, Universidade de São Paulo. v. 7, p. 11-31, 1979. DOI: https://doi.org/10.11606/issn.2316-9052.v7i0p11-31

MORAES, A. M. L.; PAES, R. A.; HOLANDA, V. L. Micologia. Capítulo 4. p. 399-496. In: MOLINARO, E. M.; CAPUTO, L. F. G.; AMENDOEIRA, M. R. R. Conceitos e Métodos para a Formação de Profissionais em Laboratórios de Saúde, v.4, Rio de Janeiro: Escola Politécnica de Saúde Joaquim Venâncio (EPSJV); Instituto Oswaldo Cruz (IOC). 2009. 290 p.

MONTEIRO, J. S. Fungos conidiais associados a substratos vegetais submersos em fragmento florestais do bioma Amazônia, Pará, Brasil. 193 f. Tese (Doutorado). Departamento de Micologia do Centro de Ciências Biológicas. Universidade Federal de Pernambuco (UFPE). 2014.

ODUM, E. P. Fundamentos de Ecologia. 6 ed. Lisboa: Fundação Calouste Gulbenkian. 2001. 927 p.

PETER, H.; EVERT, R. F.; EICHHORN, S. E. Raven. Biologia Vegetal. 7 ed. Rio de Janeiro: Guanabara Koogan. 2007. 830 p.

PUTZKE, J.; PUTZKE, M. T. L. Os Reinos dos Fungos. Volume 1. 3 ed. Santa Cruz do Sul: EDUNISC. 2013. 665 p.

RBMA -Reserva da Biosfera da Mata Atlântica. Reserva da Biosfera da Mata Atlântica Fase VI. 2008. Revisão e Atualização dos Limites e Zoneamento da Reserva da Biosfera da Mata Atlântica em Base Cartográfica Digitalizada. [online]. Disponível em: <http://www.rbma.org.br/rbma/pdf/RBMAFaseVIDoc(Portugues).pdf >. Acessado em: setembro de 2016.

SANTANA, M. V.; ANDRADE, J. P.; MONTEIRO, J. S.; GUSMÃO, L. F. P.; BEZERRA, J. L. Microfungos associados à serapilheira na Mata Atlântica e Caatinga, Bahia, Brasil. Revista Brasileira de Biociências. v. 15, n.3, p. 135-142, 2017. URL: http://www.ufrgs.br/seerbio/ojs/index.php/rbb/article/view/3797

SHEARER, C.A.; DESCALS, E.; KOHLMEYER, B.; KOHLMEYER, J.; MARVANOVÁ, L.; PADGETT, D.; et al.,; Fungal biodiversity in aquatic habitats. Biodiversity $\begin{array}{llllll}\text { Conservation. } & \text { v. } & 16, & \text { p. } & \text { 49-67, } & \end{array}$ https://link.springer.com/article/10.1007/s10531-006-9120-z

SILVA, P. Revisão do gênero Thozetella Kuntze (anamorfo de Chaetosphaeriaceae, Ascomycota), São Paulo, Brasil. 108 f. Tese (Doutorado). Departamento de Pós-Graduação em Biodiversidade Vegetal e Meio Ambiente do Instituto de Botânica da Secretaria do Meio Ambiente, São Paulo, Brasil. 2012. 
SILVA, S. S.; SANTA IZABEL, T. S.; GUSMÃO, L. F. P. Fungos conidiais associados a substratos vegetais submersos em algumas áreas do bioma Caatinga. Rodriguésia. $v$. 65, n. 2, p. 527-538, 2014. DOI: https://doi.org/10.1590/S2175-78602014000200014

TSUI, C. K. M.; HODGKISS, I. J.; HYDE, K. D. Three new species of Aquaticola (Ascomycetes) from tropical freshwater habitats. Nova Hedwigia. v. 77, p. 161-168, 2003. DOI: https://doi.org/10.1127/0029-5035/2003/0077-0161

WONG, K. M. K.; GOH, T. K.; HODGKISS, I. J.; HYDE, K. D.; RANGHOO, V. M.; TSUI, C. M. K.; HO, W. H.; WONG, W. S; YUEN, T. C. The role of fungi in freshwater ecosystems. Biodiversity and Conservation. v. 7, p. 1.187-1.206, 1998. URL: https://link.springer.com/article/10.1023/A:1008883716975 